\title{
Cenozoic global ice-volume and temperature simulations with 1-D ice-sheet models forced by benthic $\delta^{18} \mathrm{O}$ records
}

\author{
B. DE BOER, ${ }^{1}$ R.S.W. VAN DE WAL, ${ }^{1}$ R. BINTANJA, ${ }^{2}$ L.J. LOURENS, ${ }^{3}$ E. TUENTER ${ }^{1}$ \\ ${ }^{1}$ Institute for Marine and Atmospheric Research Utrecht (IMAU), Utrecht University, Princetonplein 5, 3584 CC Utrecht, \\ The Netherlands \\ E-mail: b.deboer@uu.nl \\ ${ }^{2}$ Royal Netherlands Meteorological Institute, Wilhelminalaan 10, 3732 GK De Bilt, The Netherlands \\ ${ }^{3}$ Department of Earth Sciences, Faculty of Geosciences, Utrecht University, Budapestlaan 4, 3584 CD Utrecht,
} The Netherlands

\begin{abstract}
Variations in global ice volume and temperature over the Cenozoic era have been investigated with a set of one-dimensional (1-D) ice-sheet models. Simulations include three ice sheets representing glaciation in the Northern Hemisphere, i.e. in Eurasia, North America and Greenland, and two separate ice sheets for Antarctic glaciation. The continental mean Northern Hemisphere surface-air temperature has been derived through an inverse procedure from observed benthic $\delta^{18} \mathrm{O}$ records. These data have yielded a mutually consistent and continuous record of temperature, global ice volume and benthic $\delta^{18} \mathrm{O}$ over the past $35 \mathrm{Ma}$. The simple 1-D model shows good agreement with a comprehensive 3-D ice-sheet model for the past $3 \mathrm{Ma}$. On average, differences are only $1.0^{\circ} \mathrm{C}$ for temperature and $6.2 \mathrm{~m}$ for sea level. Most notably, over the $35 \mathrm{Ma}$ period, the reconstructed ice volume-temperature sensitivity shows a transition from a climate controlled by Southern Hemisphere ice sheets to one controlled by Northern Hemisphere ice sheets. Although the transient behaviour is important, equilibrium experiments show that the relationship between temperature and sea level is linear and symmetric, providing limited evidence for hysteresis. Furthermore, the results show a good comparison with other simulations of Antarctic ice volume and observed sea level.
\end{abstract}

\section{INTRODUCTION}

The history of the Earth over the past $65 \mathrm{Ma}$ (the Cenozoic) is characterized by a general cooling trend from a 'greenhouse' to an 'icehouse' world (Lear and others, 2000). The variability in climate has increased considerably over time from a world with little continental ice prior to $\sim 34 \mathrm{Ma}$ to an icedominated climate after this transition (e.g. Liu and others, 2009). This variability is strongly reflected in benthic deepsea sediment records (Zachos and others, 2001), which serve as a proxy for global ice volume and local deep-water temperature (e.g. Chappell and Shackleton, 1986; Bintanja and others, 2005a).

In this study, both sea level and temperature over the second half of the Cenozoic era have been investigated with axisymmetrical one-dimensional (1-D) ice-sheet models (Wilschut and others, 2006) simulating glaciations on both hemispheres using benthic $\delta^{18} \mathrm{O}$ as model forcing. The continental mean surface-air temperature for the Northern Hemisphere $(\mathrm{NH})$ has been reconstructed with an inventive inverse procedure. This procedure linearly relates the $\mathrm{NH}$ temperature to the difference between the modelled and observed benthic $\delta^{18} \mathrm{O} 100$ years later (Bintanja and others, 2005a). As a result, a mutually consistent and continuous record of benthic $\delta^{18} \mathrm{O}$, sea level and temperature has been obtained over the past $35 \mathrm{Ma}$ with a $0.1 \mathrm{ka}$ resolution. Moreover, the sea-level record has been derived from ice-volume fluctuations representative of all significant continental ice sheets that existed during the past $35 \mathrm{Ma}$.

Simulations have been performed with five hypothetical ice sheets: in the $\mathrm{NH}$, two contintental ice sheets represent glaciation on the Eurasian (EAS) and North American (NAM) continents, respectively, and another ice sheet simulates the
Greenland ice sheet (GIS). Antarctic glaciation has been simulated with two separate ice sheets. This separation was included to create a more climate-sensitive West Antarctic ice sheet (WAIS), i.e. to make it more responsive to temperature and sea-level fluctuations than the East Antarctic ice sheet (EAIS). Furthermore, key processes for simulating ice-sheet evolution have been included in the model such as the feedback mechanisms between mass balance and albedo and between surface height and surface mass balance, as well as adjustment for the underlying bedrock.

\section{MODEL FORMULATION}

The model is an axisymmetrical 1-D ice-sheet model that simulates ice flow over an initially cone-shaped 'continent', i.e. with a constant negative bedrock slope in the radial direction (values and constants are listed in Tables 1 and 2 , respectively). The input for the model is benthic $\delta^{18} \mathrm{O}_{\mathrm{obs}}$ data (Lisiecki and Raymo, 2005; Zachos and others, 2008) that are used to derive the continental mean $\mathrm{NH}$ temperature with an inverse procedure (observation-constrained forward modelling), linearly relating the temperature relative to the present day, (PD), $\Delta T$, to the difference between the modelled and observed benthic $\delta^{18} \mathrm{O} 100$ years later (Bintanja and others, 2005a):

$$
\Delta T=\overline{\Delta T_{\mathrm{pm}}}+c\left[\delta^{18} \mathrm{O}_{\mathrm{b}}(t)-\delta^{18} \mathrm{O}_{\mathrm{obs}}(t+0.1 \mathrm{ka})\right],
$$

where $\overline{\Delta T_{\mathrm{pm}}}$ is the mean $\mathrm{NH}$ temperature $\left({ }^{\circ} \mathrm{C}\right)$ of the preceding (pm) 1000 years and $c$ represents the temperature response with respect to changes in the observed $\delta^{18} \mathrm{O}_{\text {obs }}$ record, per 100 years (Table 2). These values were determined by minimizing the difference between modelled and 
Table 1. Model parameters for the five ice sheets

\begin{tabular}{|c|c|c|c|c|c|c|}
\hline Parameter & Description & EAS & NAM & GIS & EAIS & WAIS \\
\hline$H_{\mathrm{bc}}$ & Central height of the bed $(\mathrm{m})$ & 1250 & 1400 & 800 & 1450 & 400 \\
\hline $\mathrm{d} b / \mathrm{d} x$ & Bedrock slope & 0.0016 & 0.0017 & 0.0014 & 0.001 & 0.0011 \\
\hline$P_{0}$ & Uncorrected precipitation $\left(\mathrm{ma}^{-1}\right)$ & 1.0 & 1.3 & 1.1 & 0.6 & 1.0 \\
\hline$R_{C}$ & Critical radius $(\mathrm{km})$ & 1700 & 2200 & 700 & 2000 & 700 \\
\hline$\beta_{T}$ & Isotopic sensitivity $\left(\%{ }^{\circ} \mathrm{C}^{-1}\right)$ & 0.35 & 0.35 & 0.35 & 0.6 & 0.8 \\
\hline$\beta_{Z}$ & Isotopic lapse rate $\left(\% \mathrm{~km}^{-1}\right)$ & -6.2 & -6.2 & -6.2 & -11.2 & -11.2 \\
\hline$N_{\text {grid }}$ & Number of gridpoints & 100 & 100 & 100 & 120 & 100 \\
\hline$\Delta l$ & Grid size $(\mathrm{km})$ & 25 & 25 & 15 & 20 & 15 \\
\hline$\delta T_{\mathrm{NH}}$ & Temp. difference from Northern Hemisphere $\left({ }^{\circ} \mathrm{C}\right)$ & & & -4 & -10 & -6 \\
\hline $\mathrm{PD} \Delta S$ & PD ice volume (m s.e.) & & & 7 & 56 & 7 \\
\hline $\mathrm{PD} \delta^{18} \mathrm{O}_{\mathrm{i}}$ & PD ice-sheet isotopic content (\%o) & & & -36 & -55 & -42 \\
\hline
\end{tabular}

observed $\delta^{18} \mathrm{O}$, i.e. the observed $\delta^{18} \mathrm{O}_{\mathrm{obs}}$ record must be accurately followed.

The derived $\mathrm{NH}$ temperature was used to run the icesheet model in forward mode over 100 years, as shown in Figure 1. The temperature anomaly is used in two procedures: the ice-sheet model (left) and the evaluation of the deep-water temperature anomaly $\Delta T_{\mathrm{O}}$ (right). Within the ice-sheet model, the isotopic content and ice volume are calculated with a time-step of 1 month and are fed into the ocean isotope module. Global sea level relative to PD is internally calculated from all ice volumes. After each output time-step of 100 years, the modelled benthic isotope $\left(\delta^{18} \mathrm{O}_{\mathrm{b}}\right.$, Equation (2)) is evaluated and forwarded to the inverse method to calculate the temperature anomaly for the next time-step.

The inverse method is based on the fact that the two dominant contributions to the benthic $\delta^{18} \mathrm{O}_{\mathrm{b}}$ signal, i.e. ice volume and deep-water temperature, are closely related to the mid-latitude-to-subpolar $\mathrm{NH}$ temperature, which controls the waxing and waning of the EAS and NAM ice sheets (Bintanja and others, 2005a). The derived surface-air temperature anomaly $\Delta T$ is therefore representative of both continents and can be directly applied to the EAS and NAM ice-sheet models.

To apply the temperature anomaly $\Delta T$ to the Antarctic and Greenland ice sheets, however, a temperature difference from EAS/NAM ice sheets needs to be derived. This

Table 2. Constants used in the model; values are adopted from Wilschut and others (2006) except for the tuning parameters used in Equation (1)

\begin{tabular}{llc}
\hline Constant & Description & Value \\
\hline$f_{\mathrm{d}}$ & Deformation parameter $\left(\mathrm{Pa}^{-3} \mathrm{~s}^{-1}\right)$ & $3.2 \times 10^{-23}$ \\
$f_{\mathrm{s}}$ & Sliding parameter $\left(\mathrm{Pa}^{-3} \mathrm{~m}^{2} \mathrm{~s}^{-1}\right)$ & $9.5 \times 10^{-19}$ \\
$T_{\mathrm{b}}$ & Relaxation time of asthenosphere $(\mathrm{ka})$ & 3 \\
$k$ & Density ratio of ice and bedrock & 3 \\
$\rho_{\mathrm{w}}$ & Density of water $\left(\mathrm{kg} \mathrm{m}^{-3}\right)$ & 1000 \\
$\rho_{\mathrm{i}}$ & Density of ice $\left(\mathrm{kg} \mathrm{m}^{-3}\right)$ & 910 \\
$\alpha_{\mathrm{g}}$ & Albedo of bare soil & 0.2 \\
$\alpha_{\mathrm{sn}}$ & Albedo of snow & 0.8 \\
$\alpha_{\mathrm{ice}}$ & Albedo of glacier ice & 0.45 \\
$\mathrm{pm}^{*}$ & averaging integration length $(\mathrm{ka})$ & 2 \\
$\mathrm{C}^{\dagger}$ & Temperature response to $\delta^{18} \mathrm{O}\left({ }^{\circ} \mathrm{C} \%{ }^{-1}\right)$ & 40 \\
\end{tabular}

\footnotetext{
*Tuning parameter.

$\dagger$ Tuning parameter. A value of 60 is used for the LR04 experiment.
}

temperature difference between the continents can be interpreted as a combination of two components: the different geographical location (i.e. a higher latitude leads to lower temperatures) and the presence of an ice sheet which lowers temperatures through feedbacks to the local climate.

The differences for the PD climate were determined by calculating the continental mean temperatures from the Climate Prediction Center dataset (1948-2008; Fan and Van den Dool, 2008) for Antarctica and from the Climate Research Unit TS3 $0.5^{\circ}$ dataset (1901-2006; Brohan and others, 2006) elsewhere. Temperatures were reduced to sea level using the PRISM (Parameter elevation Regressions on Independent Slopes Model) dataset (Edwards, 1992) with a lapse rate of $6.5^{\circ} \mathrm{C} \mathrm{km}^{-1}$, equivalent to the lapse rate used in the models.

The geographically induced differences from the $\mathrm{NH}$ continental mean temperature, $\delta T_{\mathrm{NH}}$, can be directly applied to the surface temperature calculated from the inverse routine $\Delta T$ and are listed in Table 1 . The choice of $\delta T_{\mathrm{NH}}$ is a subject for discussion, and the sensitivity of the model to different values of $\delta T_{\mathrm{NH}}$ is tested in section 3.4. For both the EAIS and GIS, however, $\delta T_{\mathrm{NH}}$ has been used to tune the volume changes to a strong volume increase of the EAIS around the Eocene-Oligocene boundary (DeConto and Pollard, 2003) and to a simultaneous initiation of the GIS with the large $\mathrm{NH}$ ice sheets, respectively. For the latter, the initiation of $\mathrm{NH}$ glaciation (and especially initiation of the

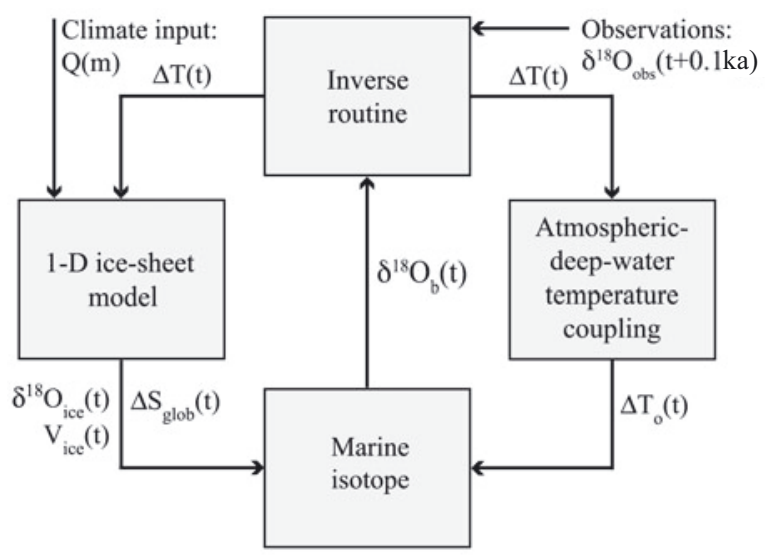

Fig. 1. The continental mean $\mathrm{NH}$ surface-air temperature anomaly from present day, $\Delta T$, is calculated every 100 years using the inverse routine described by Equation (1). 
GIS) is still under discussion (e.g. Bartoli and others, 2005), but most evidence points to an initiation around 3 Ma BP (e.g. Whitman, 1992; Sato and Kameo, 1996).

The feedback mechanism between ice sheet and climate is less straightforward and has been tested as a parameterization dependent upon the ice-sheet radius. The model outcome including this parameterization, however, did not show any large differences from the original results. We therefore excluded an additional correction to temperature in order to keep the interpretation of sea-level and temperature variations as transparent as possible.

\subsection{Including stable oxygen isotopes}

The benthic $\delta^{18} \mathrm{O}_{\text {obs }}$ data used as input for the model originate from the calcite shell of benthic foraminifera and serve as a proxy for global ice volume and local deepwater temperature (Chappell and Shackleton, 1986). The $\delta$ notation represents the ${ }^{18} \mathrm{O} /{ }^{16} \mathrm{O}$ ratio relative to the Vienna Pee Dee Belemnite (VPDB) standard. To separate the two signals we used an equation for the modelled benthic $\delta^{18} \mathrm{O}_{\mathrm{b}}$ value based on mass conservation of $\delta^{18} \mathrm{O}$ in ice and ocean water (see Appendix):

$$
\begin{aligned}
\delta^{18} \mathrm{O}_{\mathrm{b}} & =\left(\delta^{18} \mathrm{O}_{\mathrm{b}}\right)_{\mathrm{PD}}-\frac{\overline{\delta^{18} \mathrm{O}_{\mathrm{i}}} V_{\mathrm{i}}}{V_{\mathrm{O}}} \\
& +\left[\overline{\frac{\delta^{18} \mathrm{O}_{\mathrm{i}}}{V_{\mathrm{i}}}}\right]_{\mathrm{PD}}+\gamma \Delta T_{\mathrm{O}}
\end{aligned}
$$

where $V_{\mathrm{i}}$ and $V_{\mathrm{o}}$ represent the ice-sheet and ocean volume in metres sea level equivalent (m s.e.), respectively, and $\overline{\delta^{18} \mathrm{O}_{\mathrm{i}}}$ is the mean oxygen isotope content of the ice sheets $(\%)$. Listed in Table 1 are the PD values of equivalent sea level (adopted from Bintanja and others, 2002) and $\overline{\delta^{18} \mathrm{O}_{\mathrm{i}}}$ (from Lhomme and others, 2005). For the isotope content of the ice sheet, $\delta^{18} \mathrm{O}_{\mathrm{i}}$, we use the formulation introduced by Cuffey (2000):

$$
\delta^{18} \mathrm{O}_{\mathrm{i}}=\delta^{18} \mathrm{O}_{\mathrm{PD}}+\beta_{T} \Delta T+\beta_{Z} \Delta Z,
$$

where $\delta^{18} \mathrm{OPD}_{\mathrm{PD}}\left(\%_{0}\right)$ is the PD distribution over the ice sheet as a function of the mean annual temperature, corrected for surface elevation $T_{\mathrm{ma}}\left({ }^{\circ} \mathrm{C}\right)$. For the GIS we adopted the relation derived by Zwally and Giovinetto (1997):

$$
\delta^{18} \mathrm{O}_{\mathrm{PD}}=0.691 T_{\mathrm{ma}}-13.43,
$$

which is also applied to the EAS and NAM ice sheets. Although we cannot constrain the isotopic depletion of the EAS and NAM ice sheets, the $\delta^{18} \mathrm{O}_{i}$ will most probably be close to (but slightly higher than) that of the GIS. This difference, however, is included due to the applied temperature difference $\delta T_{\mathrm{NH}}$ between Greenland and NAM/EAS. For the EAIS and WAIS, we used a different equation adopted from a similar study for Antarctica:

$$
\delta^{18} \mathrm{O}_{\mathrm{PD}}=0.852 T_{\mathrm{ma}}-6.78
$$

(Giovinetto and Zwally, 1997). The additional terms in Equation (3) relate $\delta^{18} \mathrm{O}_{\mathrm{i}}$ to changes in temperature $\left({ }^{\circ} \mathrm{C}\right)$ and surface elevation $(\mathrm{km})$ with respect to PD. Values for the isotopic parameters $\beta_{T}$ and $\beta_{Z}$ are listed in Table 1 and selected within the range presented by Lhomme and others (2005).

The last term on the right-hand side of Equation (2) represents the contribution of the ocean deep-water temperature $\Delta T_{\mathrm{O}}\left({ }^{\circ} \mathrm{C}\right)$, where $\gamma=-0.28 \%{ }^{\circ} \mathrm{C}^{-1}$ (Duplessy and others,
2002). To calculate the deep-water temperature we adopted a parameterization used by Bintanja and others (2005a), for which the deep-water temperature $\Delta T_{\mathrm{O}}$ is linearly related to the $3 \mathrm{ka}$ mean $\mathrm{NH}$ temperature $\Delta T\left({ }^{\circ} \mathrm{C}\right)$ :

$$
\Delta T_{\mathrm{o}}=\lambda_{\mathrm{dw}} \Delta T_{\mathrm{m}-3 \mathrm{ka}} \cdot
$$

In this way, $\Delta T_{\mathrm{o}}$ can be seen as an $\mathrm{NH}$ mean (similar to $\Delta T$ ) deep-water temperature anomaly relative to $\mathrm{PD}$. The $3 \mathrm{ka}$ time lag can be qualitatively understood from the response timescales of the ocean with respect to the atmosphere (the former has a timescale of several ka; the latter a few months). According to Bintanja and others (2005a), longterm variations in deep-water and surface temperatures show sufficient coherence to justify the use of this relationship. Furthermore, the processes involved (e.g. vertical mixing and deep-water formation) are far too complex to include in our simplified modelling study.

The coupling coefficient $\lambda_{\mathrm{d} w}$ was determined using a simplified atmosphere-ocean climate model (Bintanja and Oerlemans, 1996) by correlating atmosphere to deepwater temperatures in a series of transient climate runs. In Bintanja and others (2005a), $\lambda_{\mathrm{dw}}=0.20$ (denoted by $\alpha$ in the supplementary information of Bintanja and Van de Wal, 2008). This value is also adopted for the $\mathrm{NH}$-only experiment. In contrast, for the full model a slightly lower value of $\lambda_{\mathrm{dw}}=0.15$ was used. This resulted in a lower reconstructed sea level during the Pleistocene with respect to the latter value, and better agreement with observed sea-level variations. A more thorough discussion of model sensitivity to this parameter is included in section 3.4.

\subsection{Ice-sheet height and bedrock adjustment}

The 1-D ice-sheet model is applied along a flowline on an equally spaced grid, although the number of gridpoints and the grid spacing is different for each ice sheet (shown in Table 1). The height of the ice sheet $H$ and the bedrock elevation $b$ (in $\mathrm{m}$ ) are explicitly calculated on each gridpoint with a time-step of 1 month. The rate of change of the icesheet height is given by the continuity equation (Van der Veen, 1999; Wilschut and others, 2006):

$$
\frac{\mathrm{d} H}{\mathrm{~d} t}=\frac{1}{r} \frac{\mathrm{d}}{\mathrm{d} r}(r H U)+B,
$$

where $U$ is the mean horizontal velocity $\left(\mathrm{m} \mathrm{s}^{-1}\right), B$ is the local surface mass balance $\left(\mathrm{ma}^{-1}\right)$ and $r$ is the distance from the centre $(m)$. The mean horizontal velocity consists of a deformation velocity, which results from driving stresses and is based on the shallow-ice approximation, and a Weertman-type sliding velocity representing velocities at the bed (Van der Veen, 1999):

$$
U=f_{\mathrm{d}} H \tau_{\mathrm{d}}^{n}+f_{\mathrm{s}} \frac{\tau_{\mathrm{d}}^{n}}{H^{\prime}}
$$

where $f_{\mathrm{d}}\left(\mathrm{Pa}^{-3} \mathrm{~s}^{-1}\right)$ is the deformation and $f_{\mathrm{s}}\left(\mathrm{Pa}^{-3} \mathrm{~m}^{2} \mathrm{~s}^{-1}\right)$ is the sliding parameter, listed in Table 2. The driving stress $\tau_{\mathrm{d}}\left(\mathrm{kg} \mathrm{m}^{-1} \mathrm{~s}^{-2}\right)$ is proportional to the ice thickness $H$ and the slope of the ice surface. $n=3$ is the exponent in Glen's flow law.

The adjustment of the bedrock to the ice load is based on the principle of local isostatic equilibrium (Van der Veen, 1999) and is given by:

$$
\frac{\mathrm{d} b}{\mathrm{~d} t}=-\frac{1}{T_{\mathrm{b}}}\left(\frac{H}{k}+b-b_{0}\right),
$$


where $T_{\mathrm{b}}$ is the relaxation time of the asthenosphere in years and $k$ is the ratio of the density of ice and the underlying bedrock material, listed in Table 2 . The initial state of the bedrock is given by $b_{0}=H_{\mathrm{bc}}-(\mathrm{d} b / \mathrm{d} x) x$, where $H_{\mathrm{bc}}$ is the central bedrock height $(\mathrm{m})$ and $\mathrm{d} b / \mathrm{d} x$ is the slope of bedrock, as listed in Table 1.

The choice of these parameters is critical for the model results; changing the bedrock slope has a significant impact on both temperature and sea level. As a second tuning target in the model, these two parameters were chosen such that the simulated $\mathrm{NH}$ ice volume at the Last Glacial Maximum (LGM, around $20 \mathrm{ka}$ ) is close to the generally established sealevel drop of $120 \pm 10 \mathrm{~m}$ (e.g. Rohling and others, 2009). For the Antarctic and Greenland ice sheets, the values were chosen such that ice volume ( $\mathrm{m} \mathrm{s.e.)}$ at PD is close to the PD value shown in Table 1.

\subsection{Mass balance}

The mass-balance parameterization is an important aspect of an ice-sheet model and serves as the coupling between temperature and ice volume. Both mass-balance components (accumulation and ablation) are calculated explicitly for each gridpoint. The ablation rate $A\left(\mathrm{~m} \mathrm{a}^{-1}\right)$ is a function of temperature and solar insolation, and is based on PD massbalance observations and modelling results for Antarctica and Greenland (Bintanja and others, 2002):

$$
A=\left[4 T_{\mathrm{ms}}+0.513(1-\alpha) Q+C_{\mathrm{abl}}\right] / 100,
$$

where $Q$ is the monthly mean incoming shortwave radiation at the top of the atmosphere $\left(\mathrm{W} \mathrm{m}^{-2}\right)$ which varies over time (Laskar and others, 2004). For each ice sheet, a different latitude was used to calculate the monthly mean values: $65^{\circ} \mathrm{N}$ for EAS and NAM; $70^{\circ} \mathrm{N}$ for GIS; and $80^{\circ} \mathrm{S}$ for EAIS and WAIS. The constant $C_{a b l}$ indicates a certain threshold value for ablation to begin, depending on temperature and insolation. For the two $\mathrm{NH}$ ice sheets, $C_{\mathrm{abl}}=-28$. This balances the PD yearly mean insolation, requiring ablation to be non-zero for temperatures above freezing.

Values for Greenland and Antarctica were based on their PD temperature differences as discussed in section 2, resulting in $C_{\mathrm{abl}}=-48,-76$ and -90 for GIS, WAIS and EAIS, respectively. Although these are slightly different from the values determined by Bintanja and others (2002), they have been selected for as much consistency as possible in the model. The temperature $T_{\mathrm{ms}}\left({ }^{\circ} \mathrm{C}\right)$ is the mean surfaceair temperature corrected for height with a lapse rate of $-6.5^{\circ} \mathrm{C} \mathrm{km}^{-1}$ and for seasonality by a superimposed sine function. The surface albedo $\alpha$ is defined:

$$
\alpha=\max \left[\alpha_{\mathrm{g}}, \alpha_{\mathrm{sn}}-\left(\alpha_{\mathrm{sn}}-\alpha_{\mathrm{su}}\right) \mathrm{e}^{-15 d}-0.015 A\right],
$$

where $\alpha_{\mathrm{g}}, \alpha_{\mathrm{sn}}$ and $\alpha_{\mathrm{su}}$ are the soil, snow and surface (soil or ice) albedo, respectively (listed in Table 2), $d$ is the snow depth $(\mathrm{m})$ and $A$ is the ablation rate at the previous time-step, calculated from Equation (8). The e-folding term represents the effect of snow thickness and patchiness on the albedo, with the snow depth determined within the model as a function of the cumulative mass balance (Bintanja and others, 2005b).

Accumulation is determined using temperature and icesheet extent. Firstly, temperature influences the moisture content of the atmosphere, i.e. higher temperatures lead to higher humidity and thus relatively more precipitation. This relation is taken into account by means of an exponential dependence on temperature $T_{\mathrm{ms}}\left({ }^{\circ} \mathrm{C}\right)$, based on the ClausiusClapeyron relation. Secondly, a bigger ice sheet prohibits the deposition of snow on the ice sheet. This is taken into account by relating the precipitation to an e-folding critical radius (Oerlemans, 2004a), approximately the maximum extent of the ice sheet:

$$
P=P_{0} \mathrm{e}^{0.04 T_{\mathrm{ms}}-R / R_{\mathrm{c}}},
$$

where $P_{0}\left(\mathrm{~m} \mathrm{a}^{-1}\right)$ is the uncorrected precipitation constant, $R$ is the radius of the ice sheet and $R_{\mathrm{C}}$ the critical radius $(\mathrm{km})$ (Table 1).

Finally, monthly snow accumulation is obtained as a temperature-dependent fraction of precipitation (Bintanja and others, 2002). The values of $P_{0}$ represent ice-sheet climate sensitivity, based on PD observational data, and are chosen such that: (1) the NH is wetter than Antarctica; (2) the WAIS is more sensitive than the EAIS; and (3) the NAM ice sheet is more sensitive than the EAS ice sheet.

\section{RESULTS}

\subsection{Validation for the Northern Hemisphere}

Firstly, to support the $35 \mathrm{Ma}$ simulations presented below, the outcome of the simplified 1-D ice-sheet model was compared to previous simulations conducted using a comprehensive three-dimensional (3-D) ice-sheet model (Bintanja and Van de Wal, 2008). Similar to the 3-D model experiment, we performed simulations over the past $4 \mathrm{Ma}$ with the EAS and NAM ice sheets only, forced with the LR04 global stack of 57 benthic $\delta^{18} \mathrm{O}$ records (Lisiecki and Raymo, 2005), linearly interpolated to a 100 year resolution. Moreover, we assumed that the $\mathrm{NH}$ ice sheets contributed to $85 \%$ of global sea level and $95 \%$ of benthic isotope variations, in agreement with the assumptions made by Bintanja and others (2005a). These two corrections were applied to Equations (A5) and (2), respectively.

Over the past $3 \mathrm{Ma}$, the results for $\mathrm{NH}$ glaciation simulations with the 1-D model are similar to the 3-D model results (Bintanja and Van de Wal, 2008), as can be seen in Figure 2. On average, the absolute differences are $1.0^{\circ} \mathrm{C}$ for $\mathrm{NH}$ temperature and $6.2 \mathrm{~m}$ for sea level. The difference (rootmean-square) between modelled and observed benthic $\delta^{18} \mathrm{O}$ is very small and less than $0.005 \%$. Furthermore, the orbital frequencies present in the benthic isotope signal (see Lisiecki and Raymo, 2007) are reproduced by temperature and ice volume. This is illustrated for temperature in Figure 3, which clearly shows the shift from the $41 \mathrm{ka}$ world to the $100 \mathrm{ka}$ glacial cycles of the late Pleistocene.

Generally, temperatures in the 1-D model are higher than in the 3-D model. The timing of maxima and minima agrees well with the 3-D model, also supported by the similarity of the power spectra (not shown). Sea-level differences are relatively smaller, although ice-sheet growth is initiated at a few degrees above PD. This is in contrast to the 3-D model (Bintanja and Van de Wal, 2008), for which a threshold of $-5^{\circ} \mathrm{C}$ was observed. As already pointed out by Wilschut and others (2006), the simplified geometry of the 1-D model is the major cause of the dissimilarities between the two models.

\subsection{A $35 \mathrm{Ma}$ record of sea level and temperature}

For the complete simulation including ice sheets in both hemispheres we used the updated composite benthic $\delta^{18} \mathrm{O}$ dataset of Zachos and others (2008), shown in Figure 4a, 


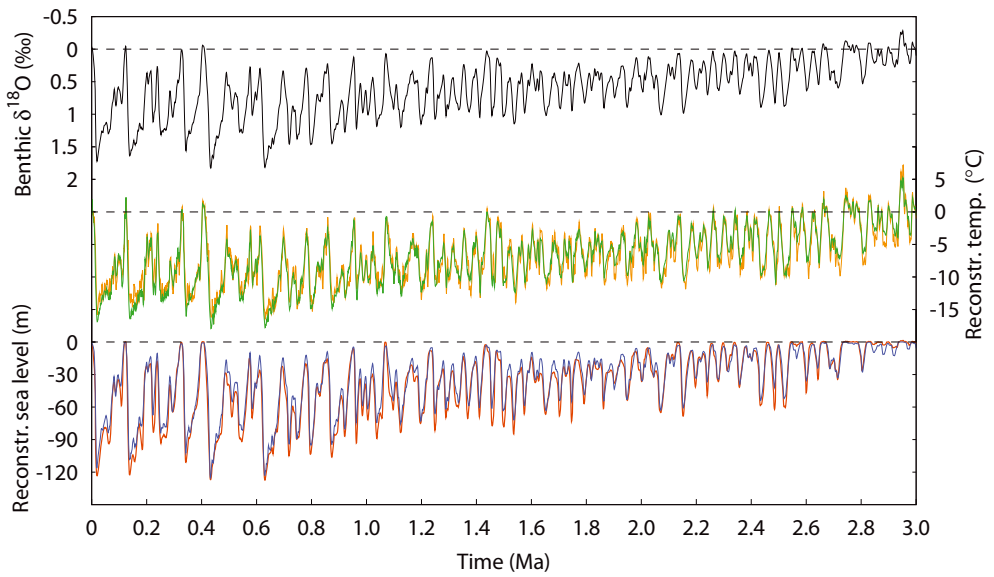

Fig. 2. Reconstructions over the past $3 \mathrm{Ma}$. From top to bottom, the LR04 (Lisiecki and Raymo, 2005) global stack of benthic $\delta^{18} \mathrm{O}$ in black; 1-D model reconstructed NH temperature in green; and global sea level in blue. The 3-D model results (Bintanja and Van de Wal, 2008) are shown in orange for temperature and in red for sea level. All values are relative to PD.

smoothed over eight data points and linearly interpolated to 100 year resolution. As can be seen in Figure $4 \mathrm{~b}$ and c showing reconstructed sea level (blue) and temperature (green), respectively, both variables closely follow the pattern of the $\delta^{18} \mathrm{O}$ record as for the $\mathrm{NH}$-only experiment discussed in section 3.1 .

The lower part of Figure $4 \mathrm{~b}$ shows the average standard deviation (a measure of variability) of $\mathrm{NH}$ and Antarctic icevolume change (in m s.e.) over 400 ka periods. Clearly visible is the strong increase of $\mathrm{NH}$ glacial variability beginning at around $5 \mathrm{Ma}$, illustrating the waxing and waning of the EAS and NAM ice sheets in the Pleistocene.

Summarized in Table 3 are the tuning targets (or model constraints) for our simulations which are all met. Sea level at the LGM, however, is around $100 \mathrm{~m}$ below PD due to a lower amplitude in the Zachos and others (2008) record compared to the LR04 forcing (Lisiecki and Raymo, 2005). For the NHonly experiment, constraint 3 in Table 3 is therefore satisfied. Furthermore, the difference between modelled and observed $\delta^{18} \mathrm{O}$ remains within $0.005 \%$. Other prominent features in the history of the Antarctic ice sheet, such as the short drop in sea level around the Oligocene-Miocene boundary (Mi$1 ; \sim 23 \mathrm{Ma}$ ) and the increase in ice volume in the mid- to late Miocene (15-10 Ma) (Zachos and others, 2001) are well reconstructed by the model.

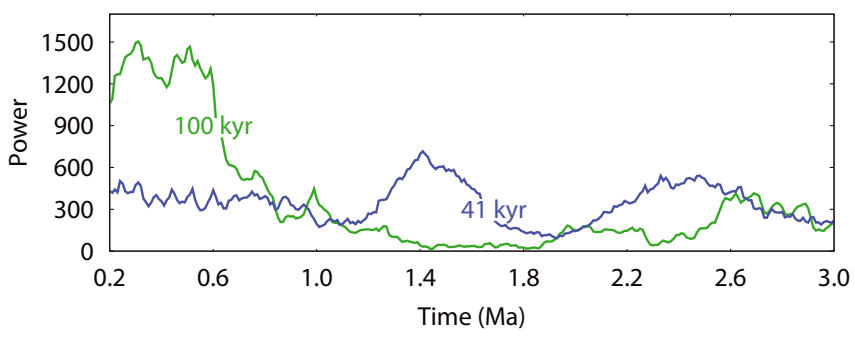

Fig. 3. Change of the $100 \mathrm{ka}$ (green) and $41 \mathrm{ka}$ (blue) frequency power of reconstructed $\mathrm{NH}$ temperature over the past $3 \mathrm{Ma}$. We applied a Blackman-Tukey spectral analysis with a Parzen window, $95 \%$ confidence limits and 3600 lags (90\% of the data) to a moving window of $400 \mathrm{ka}$ shifting with $10 \mathrm{ka}$ (361 data points in total). Analysis was conducted using the AnalySeries program (version 2.0.3; Paillard and others, 1996).
The two separate signals of the $\delta^{18} \mathrm{O}_{\mathrm{b}}$ record are shown in Figure 5, illustrating the large variability in contributions of deep-water temperature and ice volume to the total $\delta^{18} \mathrm{O}_{\mathrm{b}}$ signal. Although the variability is large, some distinct features can be recognized. Firstly, ice volume is the dominant signal during the Oligocene and the early to mid-Miocene, contributing to about $60 \%$ of changes in benthic $\delta^{18} \mathrm{O}_{\mathrm{b}}$.

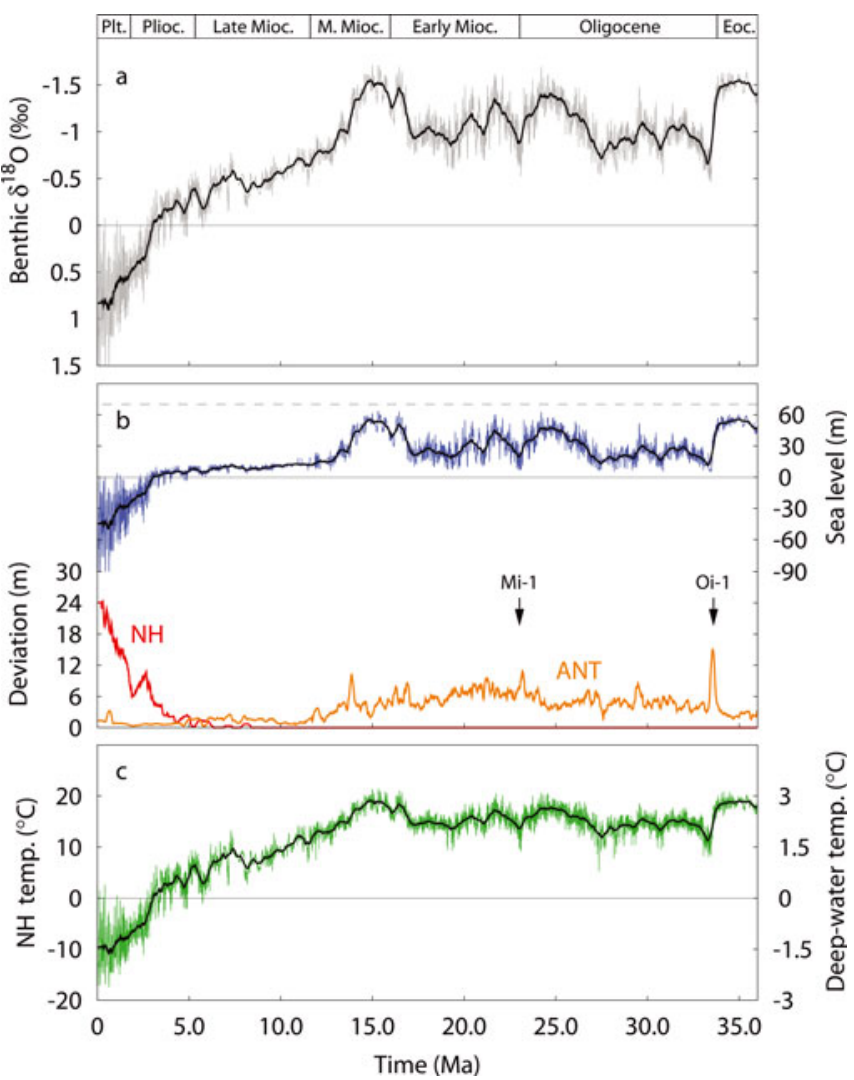

Fig. 4. (a) The Zachos benthic $\delta^{18} \mathrm{O}$ data input (grey) over the past 35 Ma relative to PD $(3.23 \%$ ). (b) Reconstructed sea level (blue) with the average standard deviation of the ice sheets calculated over $400 \mathrm{ka}$ periods for the $\mathrm{NH}$ (red) and Antarctic (orange). (c) Reconstructed temperature (green). All values are relative to PD, and black lines represent the 400 ka running mean. 
Table 3. Tuning targets for the full Cenozoic simulations

\begin{tabular}{lll}
\hline Tuning target & Source \\
\hline 1 PD ice volume of GIS, EAIS and WAIS & Bintanja and others (2002) \\
2 LGM ice volume of $\sim 120 \mathrm{~m}$ s.e. & Rohling and others (2009) \\
3 & Oi-1 increase of EAIS of $\sim 40 \mathrm{~m}$ s.e & DeConto and Pollard (2003) \\
\hline
\end{tabular}

Secondly, during the late Miocene (around 12-13 Ma), deep-water temperature becomes the major contribution to $\delta^{18} \mathrm{O}_{\mathrm{b}}(\sim 70 \%)$. During this time interval, the modelled EAIS reached its maximum extent, resulting in little change in sea level thereafter (see Fig. 4b). Since the benthic $\delta^{18} \mathrm{O}_{\mathrm{b}}$ is still increasing during the late Miocene (see Fig. 4a), temperature lowers (see Fig. 4c) in order to satisfy the requirement that the difference between modelled and observed $\delta^{18} \mathrm{O}$ is minimized.

Thirdly, over the past $3 \mathrm{Ma}$, ice volume is again the dominant signal due to the waxing and waning of the $\mathrm{NH}$ ice sheets. The percentage contribution is only slightly larger than $50 \%$, however.

The model outcome compares favourably with individual $\delta^{18} \mathrm{O}_{\mathrm{b}}$ contributions (at the LGM) discussed in the literature. For example, Zachos and others (2001) stated a contribution of the Antarctic and $\mathrm{NH}$ ice sheets of 1.2 and $1.1 \%$, respectively. Miller and others (2005) found a slightly lower contribution of the Antarctic ice sheet, $0.8-0.9 \%$, with a similar $\mathrm{NH}$ value of $1.2 \%$. These values are similar to the outcome of our model simulations, with contributions at the LGM of 1.0 and $0.8 \%$ relative to PD, respectively.

\subsection{Equilibrium experiment}

To further highlight the transition from Southern Hemisphere (SH-) to $\mathrm{NH}$-controlled climate, we conducted an equilibrium experiment using a stepwise changing $\delta^{18} \mathrm{O}$ as input, with steps of $0.1 \%$. The experiment was initiated at a $\delta^{18} \mathrm{O}$ value of $1.1 \%$ then increased to a maximum value of $5.1 \%$, from which $\delta^{18} \mathrm{O}$ was reduced back to the initial value. Each $\delta^{18} \mathrm{O}$ value was kept constant for $60 \mathrm{ka}$ allowing the ice sheets to develop to a steady state, resulting in an equilibrium temperature and sea level corresponding to every $\delta^{18} \mathrm{O}$ value.

The experiment shows little hysteresis (Fig. 6; black line). An almost equal relationship between temperature and sea level is present compared to the transient experiment (blue boxes with bars). The shift from $\mathrm{SH}$ - to $\mathrm{NH}$-dominated climate is well illustrated by the transition period centred

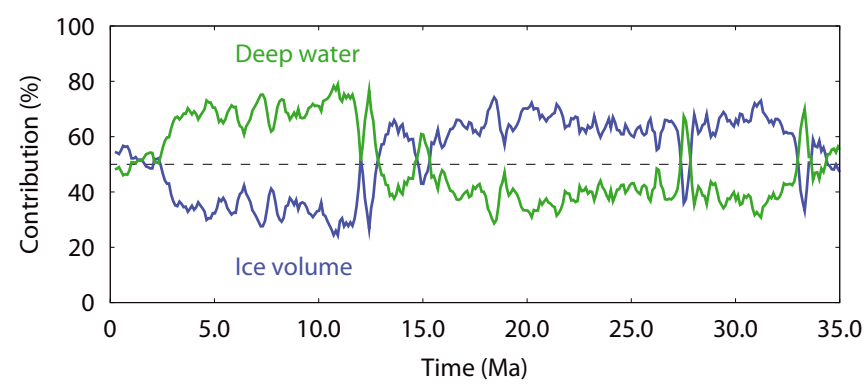

Fig. 5. Percentage contribution of deep-water temperature (green) and ice volume (blue) to changes in benthic $\delta^{18} \mathrm{O}_{\mathrm{b}}$ over the past $35 \mathrm{Ma}$, plotted as a $400 \mathrm{ka}$ running mean.

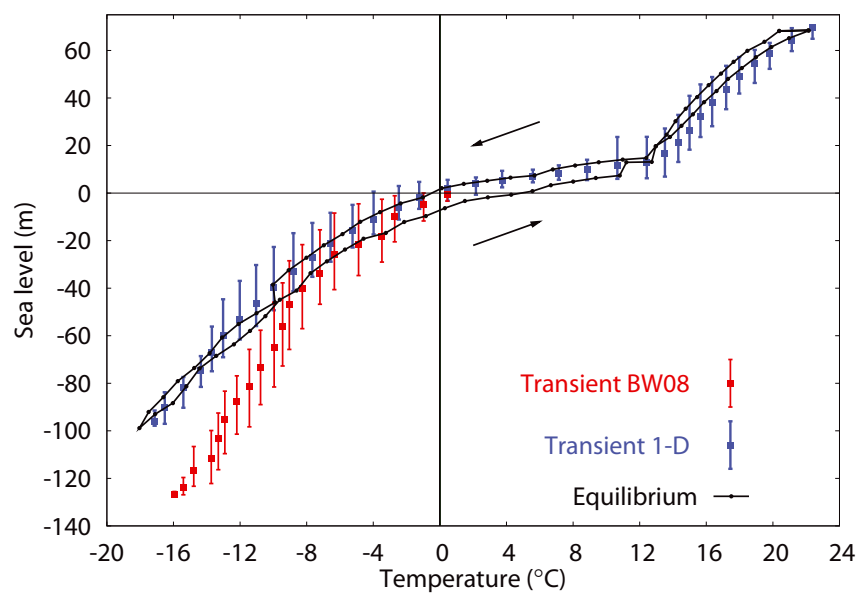

Fig. 6. The equilibrium experiment plotted for each $\delta^{18} \mathrm{O}$ step (black); arrows indicate the direction of stepwise changing $\delta^{18} \mathrm{O}$. Average sea level and temperature from the transient simulations for each $\delta^{18} \mathrm{O}$ value (within a range of $\pm 0.05 \%$ ): 1 Ma run of the 3-D model (red) and $35 \mathrm{Ma}$ transient run of the 1-D model (blue). The bars indicate the range in sea level.

around interglacial temperatures $\left(\sim 0-8^{\circ} \mathrm{C}\right.$ above PD). This indicates that interglacials are relatively stable periods compared to ice-volume change over the past $35 \mathrm{Ma}$, with the Antarctic ice sheet being in a more or less steady state and featuring minor to no glaciation in Eurasia and North America.

The red boxes with bars in Figure 6 represent the transient simulations with the 3-D ice-sheet model (Bintanja and Van de Wal, 2008) over the past $1 \mathrm{Ma}$. The results are similar to the 1-D model (in blue) for temperatures until $\sim 8^{\circ} \mathrm{C}$ below PD. For lower temperatures, however, there is a significant difference between the two models, for which the 1-D model results reveal lower temperatures for the same ice volume. These differences are mainly due to the inclusion of slightly different isotopic equations, such as Equations (2) and (3), and due to the simplified geometry. As was also mentioned by Wilschut and others (2006), the lack of hysteresis can also be ascribed to the simplified geometry of the 1-D model.

\subsection{Sensitivity tests}

A large number of parameters in the model can be varied to satisfy the tuning targets implemented in our methods, which are shown in Table 3. Two parameters, i.e. the deep-water to surface-air temperature coefficient $\lambda_{\mathrm{dw}}$ and the temperature difference with the $\mathrm{NH}$ ice sheets, $\delta T_{\mathrm{NH}}$, were investigated for their sensitivity to model results.

Because the model includes ice sheets in both hemispheres, the outcome of the sensitivity experiments can be divided into two regimes: (1) before inception of $\mathrm{NH}$ ice sheets with higher than PD temperatures and (2) a regime including ice in the $\mathrm{NH}$ with temperatures (on average) lower than PD, roughly the past $3 \mathrm{Ma}$. As is implemented in our methods, the modelled $\delta^{18} \mathrm{O}_{\mathrm{b}}$ closely follows the observed $\delta^{18} \mathrm{O}_{\mathrm{obs}}$ record. In order to satisfy this requirement, each change in deep-water temperature or ice volume is compensated by its counterpart (see Equation (2) or (A3)).

This is also shown in Table 4; the rightmost two columns list the changes in contribution to $\delta^{18} \mathrm{O}_{\mathrm{b}}$ (equal in magnitude and of opposite sign). For experiment $A$, we replaced the deep-water to surface-air temperature coefficient $\lambda_{\mathrm{dw}}$ by the values shown in the table. The changes are shown with 
Table 4. Averaged changes of the two sensitivity experiments over the two periods

\begin{tabular}{|c|c|c|c|c|}
\hline \multirow[t]{2}{*}{ Experiment } & $\begin{array}{c}\mathrm{NH} \\
\text { temp. }\end{array}$ & Sea level & $\begin{array}{l}\text { Ice volume } \\
\text { contribution }\end{array}$ & $\begin{array}{l}\text { Deep-water } \\
\text { contribution }\end{array}$ \\
\hline & ${ }^{\circ} \mathrm{C}$ & $\mathrm{m}$ & $\% 0$ & $\% 0$ \\
\hline \multicolumn{5}{|l|}{ A: $35-3 \mathrm{Ma}$} \\
\hline$\lambda_{d w}=0.25$ & -1.32 & -5.01 & 0.07 & -0.07 \\
\hline$\lambda_{\mathrm{dw}}=0.15$ & 1.68 & 6.97 & -0.09 & 0.09 \\
\hline \multicolumn{5}{|l|}{ A: $3 \mathrm{Ma}$ to PD } \\
\hline$\lambda_{\mathrm{dw}}=0.25$ & 0.51 & 4.03 & -0.05 & 0.05 \\
\hline$\lambda_{\mathrm{dw}}=0.15$ & -1.27 & -4.90 & 0.03 & -0.03 \\
\hline \multicolumn{5}{|l|}{ B: $35-3 \mathrm{Ma}$} \\
\hline$\delta T_{\mathrm{NH}}+4$ & -2.19 & 6.98 & -0.09 & 0.09 \\
\hline$\delta T_{\mathrm{NH}}-4$ & 1.82 & -5.39 & 0.08 & -0.08 \\
\hline \multicolumn{5}{|l|}{ B: $3 \mathrm{Ma}$ to PD } \\
\hline$\delta T_{\mathrm{NH}}+4$ & 0.08 & -0.86 & 0.00 & 0.00 \\
\hline$\delta T_{\mathrm{NH}}-4$ & 0.47 & 1.85 & 0.02 & -0.02 \\
\hline
\end{tabular}

respect to the result with a value of $\lambda_{d w}=0.20$. For experiment $\mathrm{B}$, the difference between Antarctica and the $\mathrm{NH}$ ice sheet, $\delta T_{\mathrm{NH}}$, was increased/decreased by $4^{\circ} \mathrm{C}$. Changes are shown with respect to $\delta T_{\mathrm{NH}}=-10$ and $-6^{\circ} \mathrm{C}$ for the EAIS and WAIS, respectively.

\section{Experiment A: deep-water temperature}

A topic which was also addressed with the 3-D model (Bintanja and Van de Wal, 2008) is the coupling between deep-water and surface-air temperature. This relationship is based on an idealized climate-ocean model that linearly relates the deep-water temperature to the $3 \mathrm{ka}$ mean $\mathrm{NH}$ temperature; see Equation (4). Bintanja and Van de Wal (2008) used a value of 0.20 for $\lambda_{d w}$, which we also adopted for the $\mathrm{NH}$-only experiment described in section 3.1. Similar to the tests performed by Bintanja and Van de Wal (2008), the 1-D model was tested with two additional values for $\lambda_{\mathrm{dw}}$ (0.15 and 0.25; experiment A) as depicted in Figure 7a.

As can be seen in Table 4, changing the $\lambda_{d w}$ value resulted in coherent changes in temperature and sea level (ice volume). The parameterization within the model is adjusted by changing $\lambda_{\mathrm{dw}}$, therefore affecting the deepwater temperature calculation first. Since temperatures are calculated relative to $\mathrm{PD}$, a lower $\lambda_{\mathrm{dw}}$ results in deep-water temperatures closer to PD, i.e. deep-water temperatures are lower and higher prior to and after $3 \mathrm{Ma}$, respectively.

In order to compensate for the changes in deep-water temperature contribution to benthic $\delta^{18} \mathrm{O}_{\mathrm{b}}$, both surface temperatures and ice volume counteract the deep-water temperature changes. In summary, a lower (higher) $\lambda_{d w}$ leads to a decrease (increase) of deep-water temperatures prior to $3 \mathrm{Ma}$, resulting in higher (lower) surface temperatures and sea level, i.e. less (more) ice volume. After $3 \mathrm{Ma}$, the changes are reversed.

\section{Experiment B: north-south temperature gradient}

A second parameter which has been tested is the temperature difference from the $\mathrm{NH}$ ice sheets, $\delta T_{\mathrm{NH}}$, indicating the difference between the Antarctic (or Greenland) and $\mathrm{NH}$ continental mean temperature reduced to sea level (without any ice). Although the values shown in Table 1 are selected from a realistic range, there is still some uncertainty related

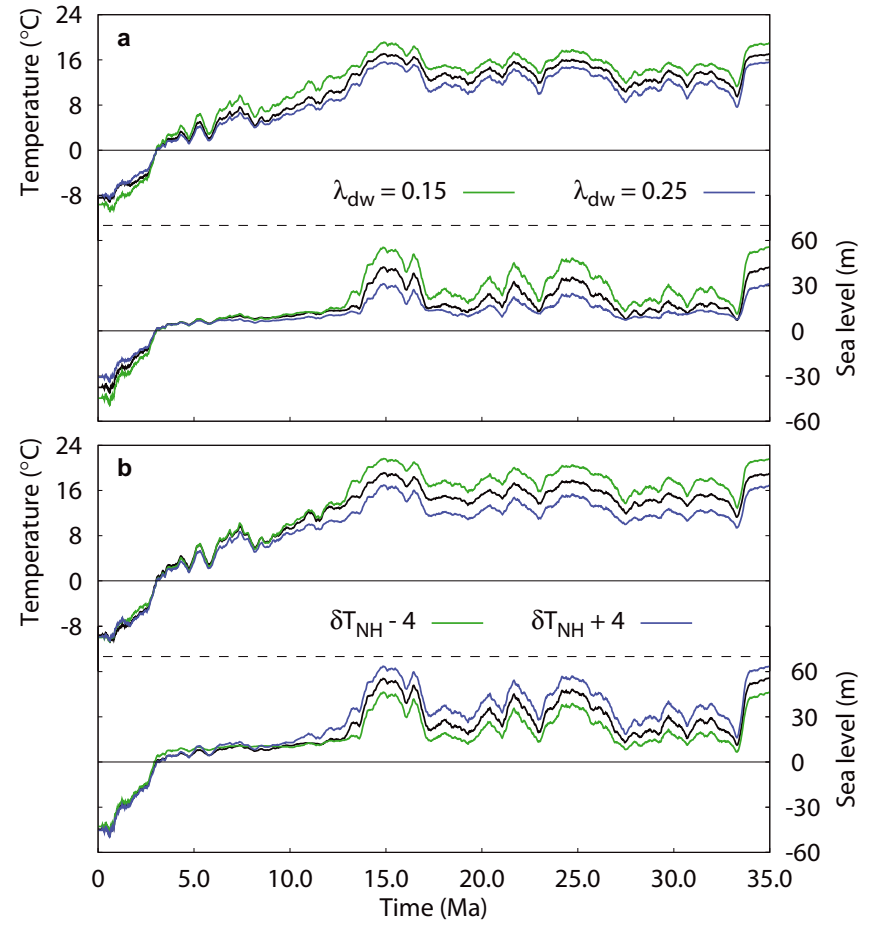

Fig. 7. Sensitivity tests performed with the model shown as $400 \mathrm{ka}$ running mean over the past $35 \mathrm{Ma}$. (a) Varying the deep-water to surface-air temperature coupling, $\mathrm{NH}$ temperature (top) and sea level (bottom) over the past $35 \mathrm{Ma}$. The default experiment with $\lambda_{\mathrm{dw}}=0.20$ is shown in black. (b) Varying the temperature difference from the $\mathrm{NH}$ ice sheets. Values indicate deviations from the gradients shown in Table 1 (black line), $\delta T_{\mathrm{NH}}=-12$ and $-8^{\circ} \mathrm{C}$ $\left(-4\right.$, green) and $\delta T_{\mathrm{NH}}=-4$ and $0^{\circ} \mathrm{C}(+4$, blue $)$ for the EAIS and WAIS, respectively.

to this parameter. Three different sets of values for Antarctica have been chosen to test the sensitivity of the model output in steps of $4^{\circ} \mathrm{C}$, i.e. $\delta T_{\mathrm{NH}}=-14$ and $-10^{\circ} \mathrm{C}$ and $\delta T_{\mathrm{NH}}=-6$ and $-2^{\circ} \mathrm{C}$ as extreme values. Central values are shown in Table 1: $\delta T_{\mathrm{NH}}=-10$ and $-6^{\circ} \mathrm{C}$ for the EAIS and WAIS, respectively.

The results with respect to the central values are presented in Figure $7 \mathrm{~b}$ and clearly show that the separate regimes are also present for this experiment. Prior to $3 \mathrm{Ma}$ the differences are quite large; for the past $3 \mathrm{Ma}$, however, changes in temperature and sea level are much smaller (Table 4). For the latter regime this is due to the limited variability of the EAIS and WAIS, as both have reached the continental margins prior to this period.

As can be seen in Figure $7 \mathrm{~b}$ and Table 4 , a reduction in ice volume is accompanied by an increase in temperature and vice versa (in contrast to experiment A). Changes prior to $3 \mathrm{Ma}$, however, are quite straightforward. Antarctic surfaceair temperature is lower when the temperature difference $\delta T_{\mathrm{NH}}$ is larger, i.e. more negative. Although precipitation is reduced due to a reduction in the moisture-holding content of the atmosphere, the accumulation increases (more snow) and ice volume is increased. To compensate for the increase in ice-volume contribution to benthic $\delta^{18} \mathrm{O}_{\mathrm{b}}$, deep-water and surface temperatures are higher.

The differences over the past $3 \mathrm{Ma}$, when temperatures are generally below $\mathrm{PD}$, are mainly due to a small reduction in EAIS volume due to a change in accumulation as a result of lower (or higher) temperatures. In summary, a 
Table 5. Comparison of model constants used in this study and by Oerlemans (2004b)

\begin{tabular}{lcc}
\hline Constant & This study & Oerlemans (2004b) \\
\hline$\Delta T_{\mathrm{o}}$ VPDB $\left({ }^{\circ} \mathrm{C}\right)$ & 8.3 & 8.9 \\
$\gamma$ and $b\left(\% 0^{\circ} \mathrm{C}^{-1}\right)$ & -0.28 & -0.25 \\
$\left(I_{\mathrm{i}} / V_{\mathrm{O}}\right)_{\mathrm{PD}}$ and $c\left(\% \mathrm{~m}^{-3}\right)$ & $3.26 \times 10^{-17}$ & $4.0 \times 10^{-17}$ \\
\hline
\end{tabular}

larger (smaller) $\delta T_{\mathrm{NH}}$ increases (decreases) ice volume prior to $3 \mathrm{Ma}$, resulting in an increase (decrease) in ice-volume contribution to $\delta^{18} \mathrm{O}_{\mathrm{b}}$. This is compensated by an increase (decrease) in deep-water and surface-air temperatures.

The choice for the parameters used in the standard experiment is based on our tuning targets. We used $\lambda_{\mathrm{dw}}=$ 0.15 because of a better agreement with Plio-Pleistocene sea-level and $\mathrm{NH}$ temperature variations. Furthermore, the choice for $\delta T_{\mathrm{NH}}$ is less significant since its influence is mostly limited to Antarctic ice volume (for which the PD ice volume and a strong increase at $\mathrm{Oi}-1$ are satisfied in all cases). The intermediate values of $\delta T_{\mathrm{NH}},-8$ and $-4^{\circ} \mathrm{C}$ for East and West Antarctica, respectively, are therefore used.

\section{DISCUSSION}

A reconstruction of global sea level and $\mathrm{NH}$ surfaceair temperature over the past $35 \mathrm{Ma}$ has been presented. Following the inverse procedure introduced by Bintanja and others (2005a) with benthic $\delta^{18} \mathrm{O}_{\text {obs }}$ as input, we have separated the $\delta^{18} \mathrm{O}_{\mathrm{b}}$ signal into an ice-volume and deepwater temperature contribution.

The results of the 1-D model, however, can be affected by several model parameters such as the deep-water to surfaceair temperature coupling $\left(\lambda_{\mathrm{dw}}\right)$ and the difference between the Antarctic and $\mathrm{NH}$ continental temperature $\left(\delta T_{\mathrm{NH}}\right)$. It has been shown that both parameters have a significant influence on the individual contributions of ice volume and temperature to the $\delta^{18} \mathrm{O}_{\mathrm{b}}$ signal. The largest differences in model results were found prior to $3 \mathrm{Ma}$. Changes in the contribution of ice volume were about $10 \%$, which are essentially changes in Antarctic ice volume as $\mathrm{NH}$ ice sheets had not yet developed.

Due to the simple geometry and the use of a fixed-grid icesheet model, the modelled Antarctic ice sheets showed little sensitivity to sea-level change. Tests have been carried out using a stretching grid, but over the past $35 \mathrm{Ma}$ differences were very small compared to the fixed-grid simulations. For these long-term changes, the low sensitivity is therefore not a concern for Antarctic ice-volume evolution.

Over the past 3-5 Ma, however, Antarctic ice volume stays more or less constant, which is not in agreement with several other studies (e.g. Conway and others, 1999; Huybrechts, 2002; Pollard and DeConto, 2009). The large sea-level fluctuations during the Pleistocene allowed the grounding line of the WAIS to migrate through the shallow Ross and Weddell Seas (Conway and others, 1999), increasing its volume significantly during glacial maxima. Although sealevel and temperature fluctuations over the Plio-Pleistocene are mainly caused by changes of the $\mathrm{NH}$ ice sheets, the simple geometry of the Antarctic ice sheets does not allow for large changes in West Antarctica. According to other modelling studies, differences in Antarctic ice volume
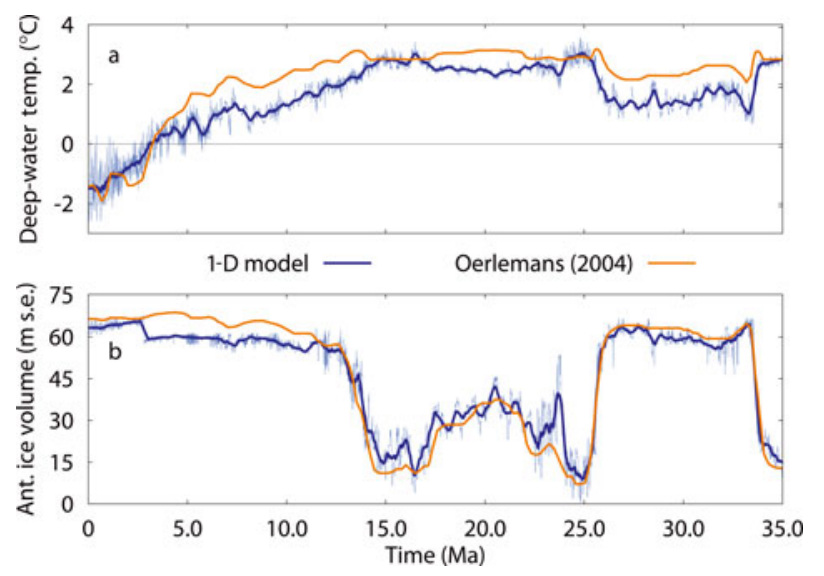

Fig. 8. Reconstructed (a) deep-water temperature relative to PD and (b) Antarctic ice volume of the 1-D model (blue). The dark blue curve is the $400 \mathrm{ka}$ running mean, and the results from Oerlemans (2004b) for $\Delta=9^{\circ} \mathrm{C}$ are in orange.

could be of the order of $10 \mathrm{~m}$ of sea level (Huybrechts, 2002). For the Pleistocene, therefore, a significant uncertainty range $(\sim 10 \%)$ can be accounted for during glacial periods.

\subsection{Comparison of reconstructed sea level}

Although there is some uncertainty related to our short-term changes, over the past 35 Ma our reconstruction of sea level and temperature is comparable to observations and other studies. For example, Oerlemans (2004b) used a continuity model for the Antarctic ice sheet to separate the deep-water temperature and ice-volume signals from the benthic $\delta^{18} \mathrm{O}_{\mathrm{b}}$ record. Overall the methodology is quite different, but in this study an axisymmetric model is also used with a sloping bed.

The method of Oerlemans (2004b) is based on a linear relation between $\delta^{18} \mathrm{O}_{\mathrm{b}}$ and both deep-water temperature and ice volume:

$$
\delta^{18} \mathrm{O}_{\mathrm{b}}=a+b T_{\mathrm{o}}+c V_{\mathrm{i}}
$$

where $a$ is related to the deep-water temperature for $\delta^{18} \mathrm{O}_{\mathrm{b}}=0$, when the stable oxygen isotope ratio is at the VPDB standard level. From Equation (11), the deepwater temperature is derived as a function of $\delta^{18} \mathrm{O}_{\mathrm{b}}$ (input) and ice volume (calculated with the model). Furthermore, the Antarctic temperature is related to the deep-water temperature (Oerlemans, 2004b, equation (7)) as a function of $\Delta$, a constant temperature difference between the deepsea and Antarctic continent, and to an additional feedback parameterization between ice sheet and climate.

For a more straightforward comparison with our methodology, Equation (11) can be restated relative to PD (similar to the treatment of Equation (A3) in the Appendix):

$$
\Delta \delta^{18} \mathrm{O}_{\mathrm{b}}=b \Delta T_{\mathrm{o}}+c \Delta V_{\mathrm{i}}
$$

When comparing Equations (12) and (A4), the biggest difference is the constant $c$; it is assumed that the isotopic content of the ice-sheet and ocean volume remains constant throughout the Cenozoic. Nevertheless, as shown in Table 5, the constants are similar to those used in our study.

A comparison of both reconstructions is shown in Figure 8, for which we used the original compilation by Zachos and others (2001) interpolated to $0.1 \mathrm{ka}$ as input for a better comparison with Oerlemans (2004b) (who used the same 
input smoothed to a 100 ka resolution). From the Eocene to the middle Miocene ( $\sim 10 \mathrm{Ma})$, our reconstructed Antarctic ice volume (blue curve in Fig. 8b) is very similar to that of Oerlemans (2004b) for $\Delta=9^{\circ} \mathrm{C}$ (shown in orange). The deep-water temperature reconstructions, however, are less similar as shown in Figure 8a. In particular, 1-D model temperatures are significantly lower during the Oligocene (33-26 Ma) and mid- to late Miocene (15-4 Ma). The average trend over the latter period, however, is comparable, with approximately equal temperatures at 15 and $4 \mathrm{Ma}$.

In addition to the comparison with other modelling results, Figure 9a shows a comparison with two long-term records over the past $35 \mathrm{Ma}$ by Müller and others (2008) (red) with error envelope and Miller and others (2005) (green). The Müller curve shows a reconstruction of the effects of changes in crustal production, sediment thickness, ocean-basin depth and area on sea level, and illustrates sea-level changes owing to long-term effects other than icevolume fluctuations. Although the mean (thick red line) curve does not show much variability over the past $35 \mathrm{Ma}$, the error envelope is significant and shows that there is still much debate about past sea-level height. Nevertheless, the volume of the ocean basin only changes by a maximum of $\sim 1 \%$ (Müller and others, 2008) and therefore shows that our assumption of a constant ocean depth and area is acceptable.

The Miller and others (2005) sea-level record (in green) prior to $9 \mathrm{Ma}$ is based on 'backstripping' a New Jersey stratigraphic record, which mainly accounts for the effects of sediment compaction, loading and water-depth variations. Changes in Antarctic ice volume are taken into account, but are smaller than the 1-D model simulations (blue curve). The record shows strong variability and, prior to $10 \mathrm{Ma}$, seems to agree more with the record of Müller and others (2008) than with our sea-level curve derived from ice volume.

Over the past $10 \mathrm{Ma}$ the similarities are evident. Over this period, however, the Miller and others (2005) record is directly derived from $\delta^{18} \mathrm{O}$ using a scaling of $0.1 \%$ per $8 \mathrm{~m}$ and correcting the data prior to $2.5 \mathrm{Ma}$ by $0.5 \%$ due to deep-ocean cooling. This is inconsistent with our findings as shown in Figure 5. Nonetheless, it is not surprising that both records show a coherent drop in averaged sea level over the past $5 \mathrm{Ma}$.

A completely independent comparison can be seen in Figure 9b, which shows past sea-level changes derived from Red Sea sediments (Rohling and others, 2009) and coral reef data from New Guinea and Barbados (Lambeck and Chappell, 2001). In terms of timing of glacial maxima, i.e. minima in sea level, the agreement is evident although the comparison for Termination $\mathrm{V}(\sim 0.42 \mathrm{Ma})$ has improved with respect to a previous reconstruction (Siddall and others, 2003). The amplitude of our reconstructed sea level (blue curve) is, however, smaller for all past terminations, mainly due to the small amplitude in the Zachos and others (2008) $\delta^{18} \mathrm{O}$ record.

\section{CONCLUSIONS}

We have presented a full ice-volume reconstruction, mutually consistent with $\mathrm{NH}$ surface-air temperatures and benthic $\delta^{18} \mathrm{O}_{\mathrm{b}}$ over the past $35 \mathrm{Ma}$, using a consistent method to derive the ice volume and temperature signal from benthic $\delta^{18} \mathrm{O}_{\mathrm{b}}$ records. The method has worked well for a
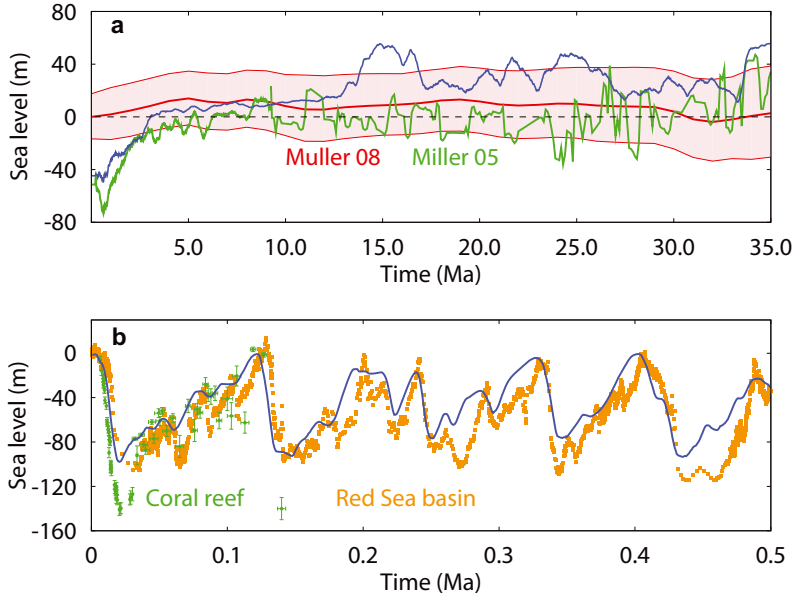

Fig. 9. Reconstructed sea level (blue) compared with other sea-level reconstructions: (a) over the past $35 \mathrm{Ma}$ with sea-level curves of Müller and others (2008) in red with error envelope and Miller and others (2005) in green; and (b) over the past 0.5 Ma with Red Sea basin sediment $\delta^{18} \mathrm{O}$ records (Rohling and others, 2009) and New Guinea and Barbados coral reef data (Lambeck and Chappell, 2001).

combination of five ice-sheet models representing glaciation of all the major ice sheets which existed during the Cenozoic.

The main result of our 1-D ice-sheet model simulation over the past $35 \mathrm{Ma}$ shows that the contributions of ice volume and deep-water temperature to the benthic $\delta^{18} \mathrm{O}_{\mathrm{b}}$ data exhibit large variations and cannot be assumed constant. Moreover, the results show a shift from a climate dominated by $\mathrm{SH}$ ice sheets to one dominated by $\mathrm{NH}$ ice sheets over the past $35 \mathrm{Ma}$, and reveal that the relationship between sea level and temperature is not constant with time.

Furthermore, it is shown that the 1-D ice-sheet model performs in line with the 3-D model results presented in Bintanja and Van de Wal (2008) over the past $4 \mathrm{Ma}$ and agrees well with observed sea-level records. The ice-sheet model, however, is a simplified representation of an actual ice sheet and has several limitations such as the unrealistic geometry, which does not support the merging of ice sheets and the formation of ice shelves. A more in-depth investigation of the associated ice-sheet dynamics, climate and sea-level changes will be presented in a future study, when we apply the same methods to the 3-D model (Bintanja and Van de Wal, 2008) including ice-sheet models for Antarctica and Greenland.

\section{ACKNOWLEDGEMENTS}

Financial support was provided by the Netherlands Organization of Scientific Research (NWO) in the framework of the Netherlands Polar Programme (NPP). Thanks are due to colleagues of the IMAU and two anonymous reviewers for providing useful comments leading to improvements in the manuscript.

\section{REFERENCES}

Bartoli, G., M. Sarnthein, M. Weinelt, H. Erlenkeuser, D. GarbeSchönberg and D.W. Lea. 2005. Final closure of Panama and the onset of northern hemisphere glaciation. Earth Planet. Sci. Lett., 237(1-2), 33-44. 
Bintanja, R. and J. Oerlemans. 1996. The effect of reduced ocean overturning on the climate of the last glacial maximum. Climate Dyn., 12(8), 523-533.

Bintanja, R. and R.S.W. Van de Wal. 2008. North American icesheet dynamics and the onset of 100,000-year glacial cycles. Nature, 454(7206), 869-872.

Bintanja, R., R.S.W. van de Wal and J. Oerlemans. 2002. Global ice volume variations through the last glacial cycle simulated by a 3-D ice-dynamical model. Quat. Int., 95-96, 11-23.

Bintanja, R., R.S.W. van de Wal and J. Oerlemans. 2005a. Modelled atmospheric temperatures and global sea levels over the past million years. Nature, 437(7055), 125-128.

Bintanja, R., R.S.W. van de Wal and J. Oerlemans. 2005b. A new method to estimate ice age temperatures. Climate Dyn., 24(2-3), 197-211.

Brohan, P., J.J. Kennedy, I. Harris, S.F.B. Tett and P.D. Jones. 2006. Uncertainty estimates in regional and global observed temperature changes: a new data set from 1850. J. Geophys. Res., 111(D12), D12106. (10.1029/2005JD006548.)

Chappell, J. and N.J. Shackleton. 1986. Oxygen isotopes and sea level. Nature, 324(6093), 137-140.

Conway, H., B.L. Hall, G.H. Denton, A.M. Gades and E.D. Waddington. 1999. Past and future grounding-line retreat of the West Antarctic ice sheet. Science, 286(5438), 280-283.

Cuffey, K.M. 2000. Methodology for use of isotopic climate forcings in ice sheet models. Geophys. Res. Lett., 27(19), 3065-3068.

DeConto, R.M. and D. Pollard. 2003. Rapid Cenozoic glaciation of Antarctica induced by declining atmospheric $\mathrm{CO}_{2}$. Nature, 421(6920), 245-248.

Duplessy, J.C., L. Labeyrie and C. Waelbroeck. 2002. Constraints on the ocean oxygen isotopic enrichment between the Last Glacial Maximum and the Holocene: paleoceanographic implications. Quat. Sci. Rev., 21(1-3), 315-330.

Edwards, M.H. 1992. Global gridded elevation and bathymetry. In Kineman, J.-J. and M.A. Ohrenschall, eds. Global ecosystems database, Version 1.0. Documentation manual (CD-ROM). Boulder CO, National Oceanic and Atmospheric Administration. National Geophysical Data Center, A14-1A14-4.

Fan, Y. and H. Van den Dool. 2008. A global monthly land surface air temperature analysis for 1948-present. J. Geophys. Res., 113(D11), D01103. (10.1029/2007JD008470.)

Giovinetto, M.B. and H.J. Zwally. 1997. Areal distribution of the oxygen-isotope ratio in Antarctica: an assessment based on multivariate models. Ann. Glaciol., 25, 153-158.

Huybrechts, P. 2002. Sea-level changes at the LGM from icedynamic reconstructions of the Greenland and Antarctic ice sheets during the glacial cycles. Quat. Sci. Rev., 21(1-3), 203-231.

Lambeck, K. and J. Chappell. 2001. Sea level change through the last glacial cycle. Science, 292(5517), 679-686.

Laskar, J., P. Robutel, F. Joutel, M. Gastineau, A.C.M. Correia and B. Levrard. 2004. A long-term numerical solution for the insolation quantities of the Earth. Astron. Astrophys., 428(1), 261-285.

Lear, C.H., H. Elderfield and P.A. Wilson. 2000. Cenozoic deepsea temperatures and global ice volumes from $\mathrm{Mg} / \mathrm{Ca}$ in benthic foraminiferal calcite. Science, 287(5451), 269-272.

Lhomme, N., G.K.C. Clarke and C. Ritz. 2005. Global budget of water isotopes inferred from polar ice sheets. Geophys. Res. Lett., 32(20), L20502. (10.1029/2005GL023774)

Lisiecki, L.E. and M.E. Raymo. 2005. A Pliocene-Pleistocene stack of 57 globally distributed benthic $\delta^{18} \mathrm{O}$ records. Paleoceanography, 20(PA1), PA1003. (10.1029/2004PA001071.)

Lisiecki, L.E. and M.E. Raymo. 2007. Plio-Pleistocene climate evolution: trends and transitions in glacial cycle dynamics. Quat. Sci. Rev., 26(1-2), 56-69.

Liu, Z. and 8 others. 2009. Global cooling during the EoceneOligocene climate transition. Science, 323(5918), 1187-1190.
Miller, K.G. and 9 others. 2005. The Phanerozoic record of global sea level change. Science, 310(5752), 1293-1298.

Müller, R.D., M. Sdrolias, C. Gaina, B. Steinberger and C. Heine. 2008. Long-term sea-level fluctuations driven by ocean basin dynamics. Science, 319(5868), 1357-1362.

Oerlemans, J. 2004a. Antarctic ice volume and deep-sea temperature during the last 50 Myr: a model study. Ann. Glaciol., 39, $13-19$.

Oerlemans, J. 2004b. Correcting the Cenozoic $\delta^{18} \mathrm{O}$ deep-sea temperature record for Antarctic ice volume. Palaeogeogr., Palaeoclimatol., Palaeoecol., 208(3), 195-205.

Paillard, D., L. Labeyrie and P. Yiou. 1996. Macintosh program performs time-series analysis. EOS, 77(39), 379.

Pollard, D. and R.M. DeConto. 2009. Modelling West Antarctic ice sheet growth and collapse through the past five million years. Nature, 458(7236), 329-332.

Rohling, E.J. and 6 others. 2009. Antarctic temperature and global sea level closely coupled over the past five glacial cycles. Nature Geosci., 2(7), 500-504.

Sato, T. and K. Kameo. 1996. Pliocene to Quaternary calcareous nanno fossil biostratigraphy of the Arctic Ocean, with reference to late Pliocene glaciation. Proc. Ocean Drill. Prog., Sci. Results, 151, 39-59.

Siddall, M. and 6 others. 2003. Sea-level fluctuations during the last glacial cycle. Nature, 423(6942), 853-858.

Van der Veen, C.J. 1999. Fundamentals of glacier dynamics. Rotterdam, A.A. Balkema.

Whitman, J.M. 1992. Pliocene-Pleistocene oxygen isotope record Site 586, Ontong Java Plateau. Mar. Micro-Palaeontol., 18(3), 171-198.

Wilschut, F., R. Bintanja and R.S.W. van de Wal. 2006. Icesheet modelling characteristics in sea-level-based temperature reconstructions over the last glacial cycle. J. Glaciol., 52(176), 149-158.

Zachos, J., M. Pagani, L. Sloan, E. Thomas and K. Billups. 2001. Trends, rhythms, and aberrations in global climate $65 \mathrm{Ma}$ to present. Science, 292(5517), 686-693.

Zachos, J.C., G.R. Deickens and R.E. Zeebe. 2008. An early Cenozoic perspective on greenhouse warming and carbon-cycle dynamics. Nature, 451(7176), 279-283.

Zwally, H.J. and M.B. Giovinetto. 1997. Areal distribution of the oxygen-isotope ratio in Greenland. Ann. Glaciol., 25, 208-213.

\section{APPENDIX: SEPARATING THE $\delta^{18}$ O SIGNAL}

The separation of the benthic $\delta^{18} \mathrm{O}$ record into an ice-volume and temperature signal is based on mass conservation of the stable oxygen isotope ${ }^{18} \mathrm{O}$.

First, we consider a simple mass conservation relation between the ratio of this isotope in ice and in the ocean water:

$$
\delta^{18} \mathrm{O}_{\mathrm{o}} V_{\mathrm{o}}+\overline{\delta^{18} \mathrm{O}_{\mathrm{i}}} V_{\mathrm{i}}=\text { constant, }
$$

where $V_{\mathrm{o}}$ and $V_{\mathrm{i}}$ are the ocean and ice volume $\left(\mathrm{km}^{3}\right.$ water equivalent), respectively, and $\delta^{18} \mathrm{O}_{\mathrm{o}}$ and $\overline{\delta^{18} \mathrm{O}_{\mathrm{i}}}$ are the ocean-water and mean ice-sheet $\delta^{18} \mathrm{O}$, respectively.

Secondly, to include the total benthic $\delta^{18} \mathrm{O}_{\mathrm{b}}$ signal, we need to subtract the deep-water contribution from the benthic data to determine the ocean-water signal and substitute this into Equation (A1):

$$
\left(\delta^{18} \mathrm{O}_{\mathrm{b}}-\gamma T_{\mathrm{o}}\right) V_{\mathrm{o}}=-\overline{\delta^{18} \mathrm{O}_{\mathrm{i}}} V_{\mathrm{i}} .
$$

The value of $\gamma$ is adopted from Duplessy and others (2002), in which they showed a linear relation between benthic $\delta^{18} \mathrm{O}$ and deep-water temperatures with a slope of $-0.28 \%{ }^{\circ} \mathrm{C}^{-1}$. 
So far we have considered absolute values of the above variables. We want, however, to calculate $\delta^{18} \mathrm{O}_{\mathrm{b}}$ with respect to $\mathrm{PD}$. To do so, first we rewrite Equation (A2):

$$
\delta^{18} \mathrm{O}_{\mathrm{b}}=-\frac{\overline{\delta^{18} \mathrm{O}_{\mathrm{i}}} V_{\mathrm{i}}}{V_{\mathrm{o}}}+\gamma T_{\mathrm{O}}
$$

which shows the separation of the ice-volume signal (first term on the right-hand side) and deep-water signal (second term on the right-hand side) of the benthic isotope signal $\delta^{18} \mathrm{O}_{\mathrm{b}}$. Secondly, Equation (A3) is restated relative to PD:

$$
\Delta \delta^{18} \mathrm{O}_{\mathrm{b}}=-\frac{\overline{\delta^{18} \mathrm{O}_{\mathrm{i}}} V_{\mathrm{i}}}{V_{\mathrm{O}}}+\left[\frac{\overline{\delta^{18} \mathrm{O}_{\mathrm{i}}} V_{\mathrm{i}}}{V_{\mathrm{O}}}\right]_{\mathrm{PD}}+\gamma \Delta T_{\mathrm{O}},
$$

where $\Delta$ denotes values relative to PD. Furthermore, $V_{\mathrm{O}}$ is calculated as the PD depth of the ocean $\left(D_{\mathrm{O}}=4 \mathrm{~km}\right)$ minus the calculated global sea level $(\Delta S)$ times the area of the world's ocean $\left(O_{\text {area }}\right)$, which is assumed to remain constant at $3.62 \times 10^{8} \mathrm{~km}^{2}$ :

$$
V_{\mathrm{o}}=\left(D_{\mathrm{o}}-\Delta S\right) O_{\text {area }} .
$$

